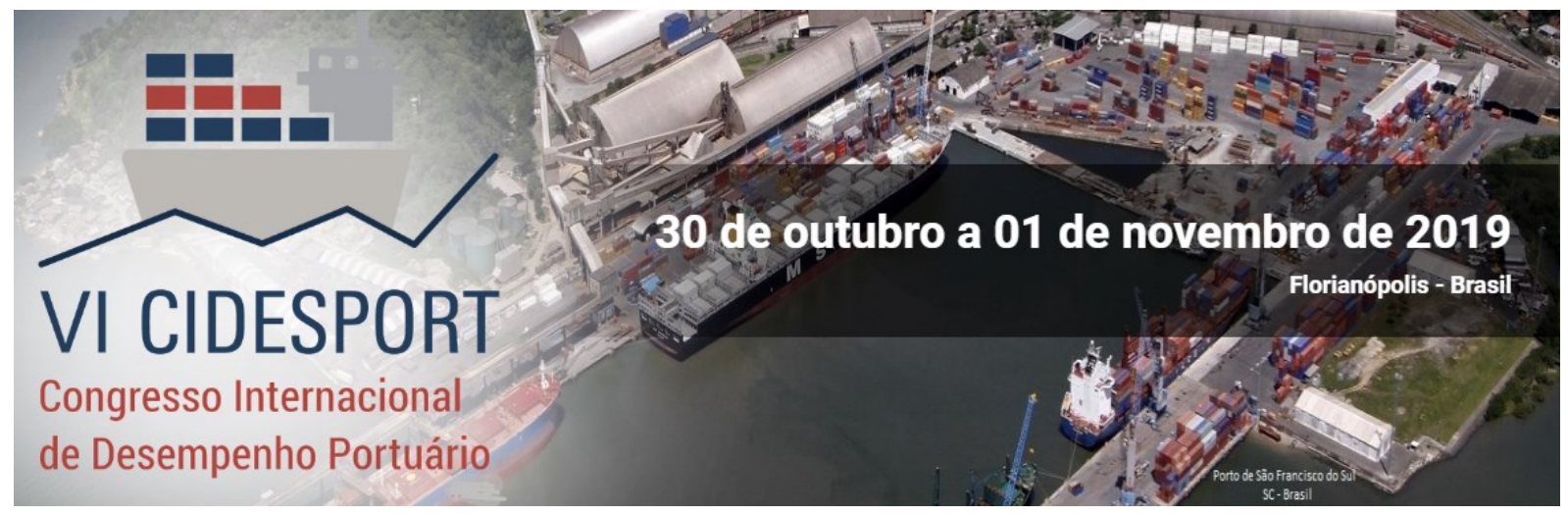

\title{
ANÁLISE DO IMPACTO ECONÔMICO DO TERMINAL PORTUÁRIO DE ALCÂNTARA
}

Sérgio Cutrim

Universidade Federal do Maranhão

Leo Tadeu Robles

Universidade Federal do Maranhão

\section{Arnóbio Matheus Vieira de Paiva Universidade Federal do Maranhão}

Resumo: Esta pesquisa teve como objetivo a análise do impacto econômico da atividade portuária, especificamente do Terminal Portuário de Alcântara. Um empreendimento greenfield, localizado no estado do Maranhão, que está em fase de desenvolvimento de projetos e obtenção de licenças, porém já aprovado pela ANTAQ. A justificativa está na difícil compreensão de quais sãos os verdadeiros benefícios da atividade portuária para uma região e um país. Algumas assimetrias informacionais impactam negativamente sobre a compreensão desses impactos e por consequência na relação porto-cidade. Foi utilizado como metodologia: pesquisa bibliográfica; pesquisa documental; entrevista e metodologia de análise de impacto econômico proposta pelo Bureau of Transport Economics da Austrália. O impacto econômico foi medido por meio do Valor dos Serviços Prestados, Valor Adicionado Bruto, Rendimento das Famílias e o Número de Empregos Gerados e foi dividido em impacto direto, indireto e induzido. Foi avaliado para um período de 24 anos (2024 a 2048). Os resultados obtidos mostraram um valor e evolução significativos, sendo que o impacto total do Valor Adicionado Bruto se inicia com R\$ 6,7 bilhões em 2024, prevendo-se atingir $\mathrm{R} \$ 70,5$ bilhões em 2048 . Em relação aos empregos, o impacto total em 2024 foi estimado em 15.159, atingindo 40.424 em 2048, o rendimento das famílias foi de $R \$ 472,1$ milhões em 2024, alcançando $R \$ 1,2$ bilhões em 2048. Esses números indicam uma oportunidade de contribuição para o desenvolvimento regional, comprovando o papel dos portos para a melhoria das condições de movimentação de produtos (riquezas) e beneficiando pessoas (geração de renda).

Palavras-chave: Impacto Econômico. Porto. Terminal Portuário de Alcântara. Grão Pará Multimodal.

\section{INTRODUÇÃO}

É reconhecido o papel que os portos desempenham como agentes de desenvolvimento econômico em suas áreas de influência, regiões em que se inserem e para as nações como elementos chaves para o comércio entre países (CUTRIM,

*A revisão gramatical, ortográfica, ABNT ou APA foi realizada pelos autores. 
BOTTER, ROBLES, 2018; MONIÉ, VIDAL, 2006). Por outro lado, são poucos os estudos de determinação e quantificação desses benefícios: renda, empregos e infraestrutura (NOTTEBOOM, RODRIGUE, 2005). Este artigo apresenta os resultados relativos ao impacto econômico da implantação do Terminal Portuário de Alcântara (TPA), empreendimento localizado na Baia de São Marcos no estado do Maranhão, pertencente a empresa Grão Pará Multimodal.

O impacto da implantação do TPA focalizou as atividades econômicas dos principais municípios diretamente afetados, ou seja, Alcântara, Pinheiro e Bequimão e suas repercussões no estado do Maranhão. Atualmente, estes municípios se dedicam à atividade agropecuária, em geral, com lavouras temporárias e de importância econômica relativamente pequena, assim como, apresentam indicadores sociais, apesar de melhoria nos últimos anos, que apontam problemas de pobreza e equidade social (IBGE,?). Essas condições potencializam o papel que o empreendimento pode representar para a população e para as atividades locais.

A metodologia de avaliação do impacto econômico objetivou a estimativa de multiplicadores entre a atividade (valores econômicos) a ser implantada e seu rebatimento nos indicadores econômicos locais (MUSSO, FERRARI, BENACCHIO, 2006). Para tanto, se utilizou uma Matriz de Insumo-Produto, ou seja, ferramenta que estima quanto da entrada de matérias-primas e insumos (inputs) é transformada em produtos (outputs) na estimativa do valor adicionado, especificamente o Valor Adicionado Bruto (VAB), na contribuição para o Produto Interno Bruto (PIB) local e os empregos gerados pelo TPA (BTE, 2001).

\section{REFERENCIAL TEÓRICO}

O artigo apresenta a caracterização do impacto econômico dos investimentos em portos nas suas regiões de implantação no nível local, regional e nacional pela quantificação dos seus conceitos em termos de Valor da Produção, Valor Adicionado Bruto (VAB), Rendimentos das Famílias e Número de Empregos, estes categorizados em diretos, indiretos e induzidos.

\subsection{O impacto econômico dos investimentos portuários}

O investimento em infraestrutura de transportes propicia às nações as condições necessárias para seu desenvolvimento econômico e social e atuação competitiva no contexto de globalização das economias. Ou seja, o investimento portuário se apresenta como importante direcionador (driver) do desenvolvimento econômico local, regional e nacional com efeitos diretos, indiretos e induzidos, como veremos adiante.

Rodrigue e Schulman (2017) afirmam que os portos agregam valor para sua região, sendo que seus benefícios econômicos e sociais se apresentam vis a vis a impactos ambientais durante sua implantação e operação. Neste trabalho, focalizamos os impactos econômicos dos investimentos portuários.

Portos se caracterizam como empreendimento capital intensivo, isto é, demandam altos investimentos de capital tanto na sua infraestrutura (canais de acesso, quebra-mares, sistemas de eclusas e barragens, obras de dragagem, píeres e cais, etc.), como na superestrutura (pórticos, equipamentos de carga e descarga, de movimentação das cargas em pátios e armazéns) e outras instalações necessárias para as operações portuárias, ou seja, a interrelação terra-água-terra (Cutrim, Botter, Robles, 2018). 
Os portos são considerados em duas dimensões: a de serviços públicos e, portanto, sujeitos à regulamentação e taxação por parte do Poder Público e a de negócio privado atuando em mercados altamente competitivos. Ambas categorias indicam a necessidade de avaliação de projetos de investimento voltados para eficiência e para resultados empresariais ou sociais positivos que remunerem o capital investido. (MUSSO et al., 2006).

No Brasil, os portos são regulamentados pelo Governo Federal e têm a configuração básica de Portos Públicos - PP (autoridade portuária pública e operação privada de terminais) e de Terminais de Uso Privativo - TUP (operados em área própria e privada mediante autorização governamental). O presente trabalho focaliza o TUP em implantação em Alcântara -MA, avaliando seus impactos econômicos e sociais.

A literatura sobre estimativa dos impactos de investimentos portuários não é muito extensa, focalizando, majoritariamente, portos individuais, sendo que identificamos poucos estudos abordando os efeitos ou impactos da implantação de portos nas suas regiões de localização ou mesmo seu reflexo no nível nacional. Ao lado da afirmação do papel dos portos no desenvolvimento das nações, tem-se que a mensuração de seus impactos no nível regional é considerada bastante dificultosa e, de certa forma imprecisa e voltada para inferências das relações econômicas (impactos) produzidas por sua implantação e atuação. (RODRIGUE; SCHULMAN, 2017).

Esses autores apresentam os impactos do investimento em portos em três tipos de mudanças, a saber:

- Mudanças econômicas - resultantes da atuação dos portos e do transporte marítimo no contexto de economias globalizadas, com realocação de recursos e redução de custos, principalmente, com a integração logística dos sistemas globais de distribuição;

- Mudanças técnicas - referente ao aumento do tamanho dos navios para exploração de economias de escala. Da mesma forma, tem-se a especialização dos navios aos diferentes tipos de carga (contêineres, granéis líquidos e sólidos, navios roll-on; roll-off, especializados no transporte de veículos sobre rodas, e outros). Mais recentemente, tem se apresentado a automação crescente da movimentação de cargas nos terminais;

- Mudanças organizacionais - aumento da participação de grandes armadoras e empresas operadoras de terminais multinacionais com a integração vertical em cadeias logísticas internacionais. (RODRIGUE; SCHULMAN, 2017).

Essas condições têm se refletido no papel dos portos do ponto de vista regional de diversas formas, por exemplo, com a exigência de extensas áreas para implantação; a atuação dos operadores dos terminais portuários voltada para o interior, ou seja, para a visão das cadeias logísticas que o usam e a criação relativamente menor de empregos ou sua indução, em comparação com um passado não tão distante. Por exemplo, a implantação e disseminação do uso de contêineres se apresentam em pouco mais que 50 anos. (LEVINSON, 2006).

Os empregos induzidos pelos investimentos portuários, segundo Rodrigue e Schulman (2017), se concentram mais em atividades de serviço do que nas industriais ou operacionais e, em função da sua automação crescente, passam a demandar mão- 


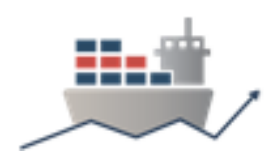

de-obra mais capacitada e com relativa maior remuneração e, assim, potencializando a renda regional.

Os benefícios econômicos dos portos têm relação clara com sua hinterlândia e decorrem do papel dos portos como catalisadores e facilitadores de atividades econômicas nas cadeias e corredores logísticos aos quais se inserem. Define-se hinterlândia como à área de influência de um porto, isto é, a região ou alcance da origem e destino verdadeiros das cargas que movimenta. Logicamente, está relacionada com as cadeias logísticas e disponibilidade de meios de transporte de e para sua localização (ROBLES, 2016). Rodrigue e Schulman (2017) dividem os impactos de investimentos portuários em diretos, indiretos e induzidos, sendo os diretos relativos aos dispêndios financeiros de implantação e os indiretos e induzidos inferidos a partir dos efeitos da atividade portuária nas economias locais e regionais.

Normalmente, apontam Rodrigue e Schulman (2017), os benefícios dos portos são quantificados em um nível agregado, correspondendo ao valor adicionado das atividades derivadas (operações e serviços) da movimentação portuária; à geração de impostos e no ponto de vista privado, o retorno do investimento realizado. Dessa forma, se referem aos montantes relativos às demandas e receitas das atividades portuárias; à sua destinação (vocação); às estratégias dos armadores e operadores; à capacidade e disponibilidade de infraestrutura de transporte de acesso à hinterlândia e à consideração dos efeitos da competição entre terminais portuários próximos ou não. A concorrência se dá na relação dos serviços e oportunidades oferecidos pela inter-relação com seus usuários e armadores que os escalam.

Essas estimativas podem se basear em pesquisas (surveys) extensivas junto aos agentes econômicos envolvidos e identificados, inclusive para os empregos gerados, tendo em vista a complexidade e extensão das relações comerciais possibilitadas pelos portos. Outra alternativa é a utilização de modelos de insumoproduto e seus multiplicadores intersetoriais (elasticidades) de relação entre os níveis de tráfego portuário e a geração regional de empregos. Pode-se também se utilizar de análises comparativas com estudos existentes de portos similares, as quais, embora não determinísticas, propiciam a visão do que pode ocorrer na relação entre um determinado porto e a economia da sua região. Estas metodologias são utilizadas neste estudo.

Rodrigue e Schulman (2017) apontam que os investimentos em portos resultam em benefícios econômicos e indicam a questão da distribuição desses benefícios nos níveis local, regional, nacional e global, como segue:

- O pessoal empregado, em geral, é da comunidade local e os benefícios (renda) são aplicados na região e irão gerar empregos indiretos, usualmente, com salários superiores à média local. Os autores citam o setor de transporte rodoviário como um dos maiores beneficiados;

- O capital aplicado, em geral, apresenta fontes nacionais ou internacionais de financiamento;

- As empresas portuárias podem ser locais, mas, a tendência é de integração vertical e horizontal com os terminais de propriedade de empresas que operam em diferentes portos no país e mesmo internacionalmente.

- O uso das áreas portuárias é regulamentado por contratos de concessão, arrendamento ou autorização para atrair investidores e que podem não refletir o valor real do impacto do investimento portuário nas terras;

- A infraestrutura de transporte local é utilizada com custos inexistentes ou baixos, representando um subsídio aos usuários e operadores portuários; 
- Os impostos e taxas aduaneiras são parcialmente transferidos para a região do porto, constituindo-se fonte de receitas para o governo nacional;

- Os impactos ambientais (poluição, ruídos, acidentes) são externalidades assumidas pela comunidade local. (RODRIGUE; SCHULMAN, 2017).

Jouili e Allouche (2016) ao estudarem os efeitos do investimento portuário na economia da Tunísia, os apontam como positivos e mais significantes para o setor de serviços e para o industrial, do que para o agrícola e recomendam sua consideração na formulação de políticas públicas para o setor. $O$ consenso é que investimentos portuários, pelo seu papel na economia das nações, propiciam benefícios positivos tanto no nível local, como regional e nacional, contribuindo para o desenvolvimento econômico e social das regiões em que se inserem.

As metodologias disponíveis para análise e quantificação de impacto econômico de atividades não são únicas e padronizadas, em especial ao se considerar o setor portuário. A maior parte das metodologias existentes está relacionada à análise da relação (impacto) de um empreendimento nos aspectos econômicos em geral, expressos em variáveis e quantitativos de receitas, emprego, salários, rendimentos e impostos. A Figura 1 apresenta um resumo dos efeitos (impactos) econômicos relacionados ao setor portuário.

Figura 1 - Impacto da indústria portuária
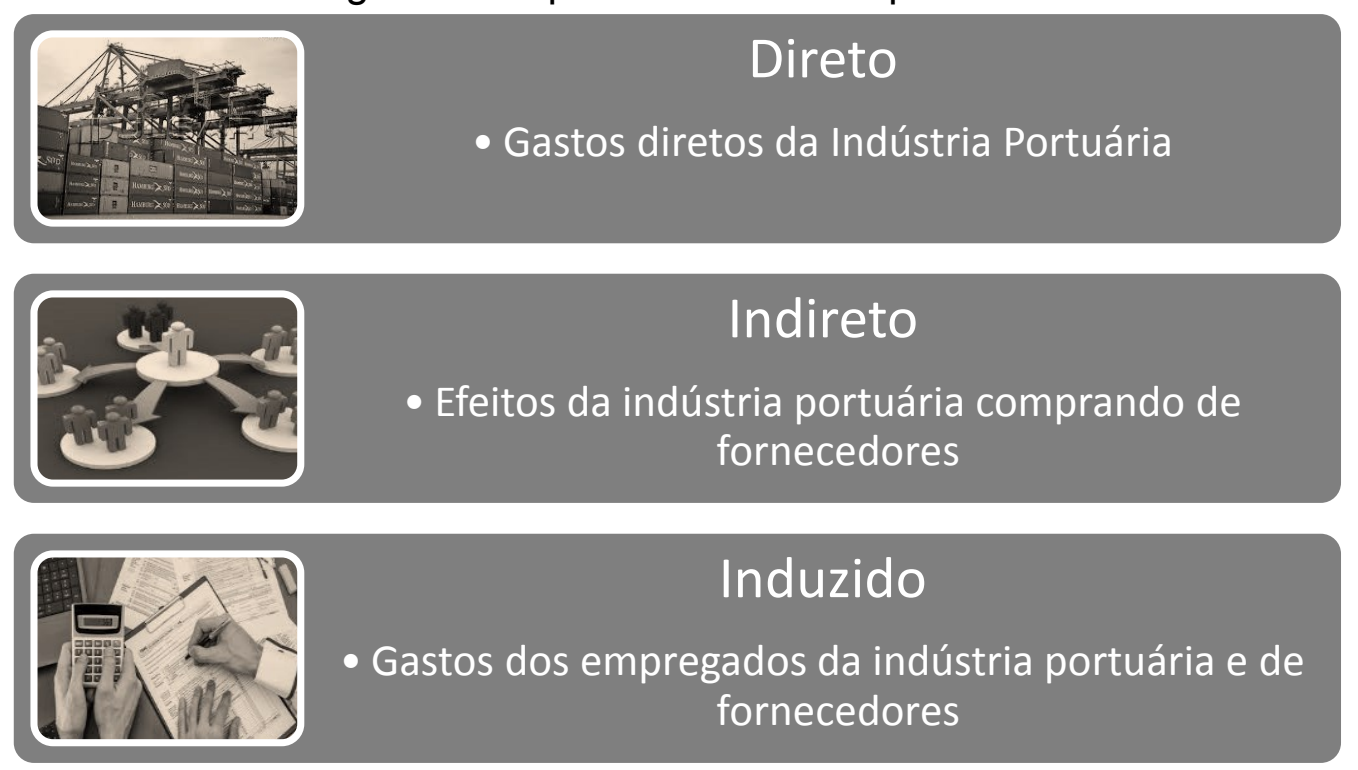

Fonte: Strauss-Wieder Incorporation (2011).

Nos setores portuários já consolidados, o impacto econômico direto se refere aos principais atores do setor portuário, conforme ilustra a Figura 2, que apresenta os usuários e intervenientes nestas atividades, de um lado os diretamente envolvidos com as operações do comércio exterior, do porto e de seu acesso terrestre e de outro, prestadores de serviços acessórios e correlatos, como agentes e despachantes de cargas e da documentação; os serviços de praticagem (responsáveis pela orientação da entrada, saída e acesso dos navios aos berços de operação); serviços de manutenção em geral; abastecimento de combustíveis e disposição adequada de resíduos. 


\section{CIDESPORT/2019 \\ Congresso Internacional \\ de Desempenho Portuário}

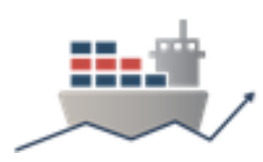

Figura 2 - Mapa de relação entre os principais atores do setor portuário

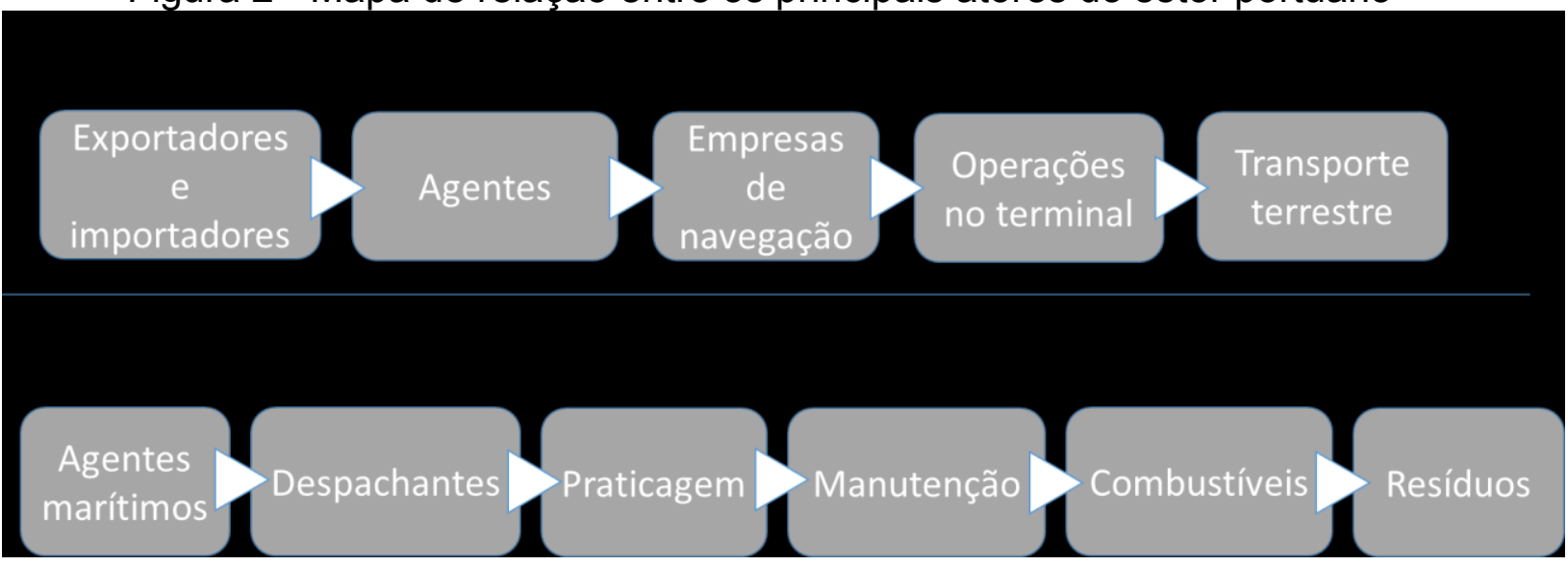

Fonte: Adaptado de Meersman, Van de Voorde e Vanelslander (2003)

O Quadro 1 descreve as atividades dos principais atores do setor portuário, desde as operações de carga e descarga, operações e serviços para os navios, a movimentação das cargas e passageiros nos terminais portuários especializados, a prestação de serviços, as atividades de sua movimentação (transporte) terrestre, compreendendo serviços de logística das cargas, implantação e manutenção da infraestrutura, da superestrutura e de equipamentos e os serviços de responsabilidade de entidades governamentais. Estas atividades são desempenhadas por um número de agentes e explicam o efeito multiplicador que a operação de um porto tem em relação à região em que se insere, conforme exploramos neste estudo. 


\section{CIDESPORT/2019}

Congresso Internacional

de Desempenho Portuário

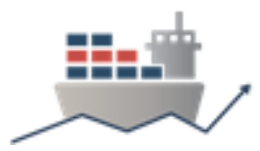

Quadro 1 - Atividades portuárias

\begin{tabular}{|c|c|}
\hline GRUPO & ATIVIDADES \\
\hline \multirow{5}{*}{ Operações Portuárias } & Plenejamento, promoção e coordenação \\
\hline & Gestão do espaço físico \\
\hline & Segurança portuária \\
\hline & Construção e manutenção de cais \\
\hline & Dragagem \\
\hline \multirow{14}{*}{ Operações e movimentações de navios } & Armadores \\
\hline & Gestor de frota de navios \\
\hline & Reparação e manutenção de navios \\
\hline & Abastecimento de combustíveis \\
\hline & Abastecimento de alimentos, ferramentas, equipamentos e etc. \\
\hline & Inspetores de cargas \\
\hline & Eliminação de resíduos \\
\hline & Agentes de navegação \\
\hline & Rebocadores \\
\hline & Praticagem \\
\hline & Rebocadores \\
\hline & Pilotos \\
\hline & Ajuda à navegação \\
\hline & Serviços relacionados a segurança \\
\hline \multirow{3}{*}{ Movimentação de mercadoria } & Estivadores \\
\hline & Carga a granel \\
\hline & Terminal de passageiros \\
\hline \multirow{4}{*}{ Serviços auxiliares a movimentação } & Despachantes aduaneiros \\
\hline & Agentes \\
\hline & Fumigação \\
\hline & Consolidadores de contêineres \\
\hline \multirow{3}{*}{ Transporte terrestre e armazenamento } & Transporte rodoviário \\
\hline & Transporte ferroviário \\
\hline & Armazém e silos \\
\hline \multirow{2}{*}{ Instituições públicas } & Autoridade portuária \\
\hline & Alfândega \\
\hline
\end{tabular}

Fonte: CEGE (2011).

A Figura 3, de forma complementar, explicita os serviços que compõem a operação portuária, assim como seus prestadores principais: Agentes marítimos, despachantes aduaneiros, práticos, empresas de rebocadores, serviços de amarração (disposição do encordoamento e amarras navio-cais), o abastecimento de combustíveis aos navios (bunkering), provisionamento de alimentação e materiais de uso pessoal das tripulações (catering), abastecimento de água, serviços de coleta de resíduos e dejetos, e serviços de desamarração (operação inversa à amarração) (Booz \& Co., 2012). Em resumo, a operação portuária é complexa, multifacetada e muito especializada e a estimativa de seus impactos econômicos requer uma metodologia sofisticada e que focalize sua repercussão em sua região em alcances diferenciados, ou seja, impactos diretos, indiretos e induzidos. 
Figura 3 - Serviços auxiliares prestados ao navio durante a operação

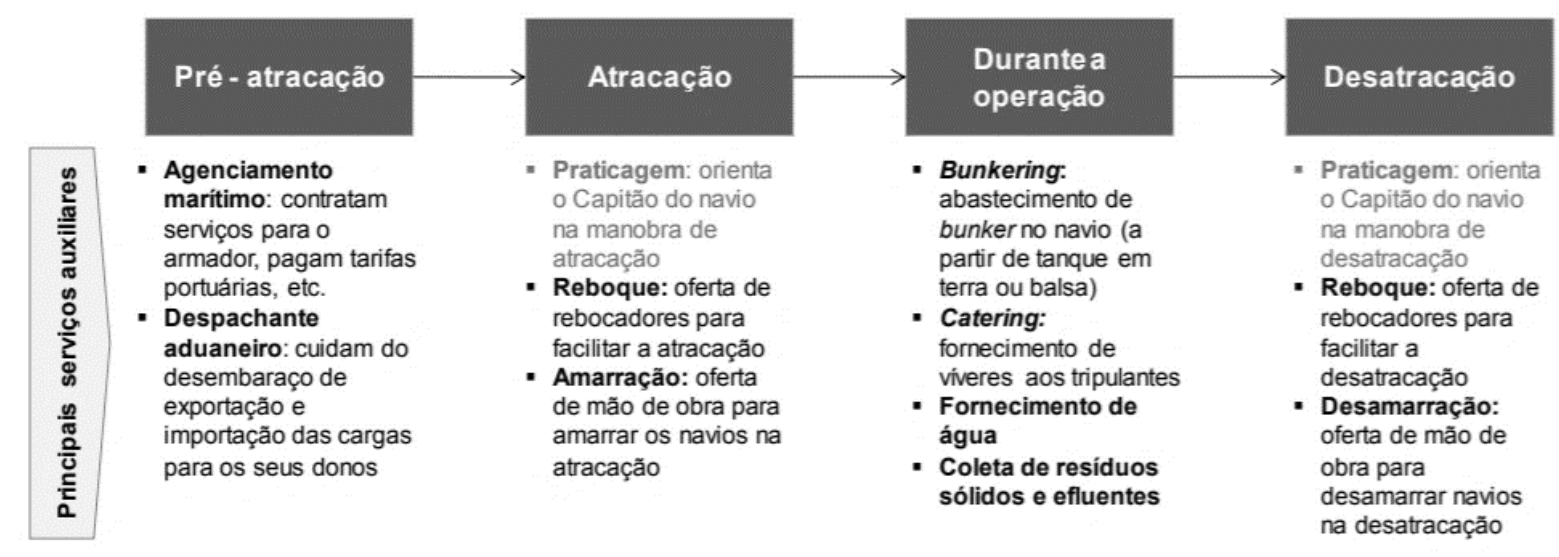

Fonte: Booz \& Co., 2012.

Um estudo de impacto econômico de empreendimentos deve se iniciar pela quantificação de sua repercussão direta, ou seja, a primeira onda de impacto na economia. Ao surgir a demanda por determinado tipo de produto ou serviço é natural que se apresente sua produção e a prestação deste serviço. O aumento de produção decorrente irá influenciar as atividades econômicas de contratação de fornecedores; de aquisição e mobilização de insumos; de contratação de empregados; de contratação de serviços terceirizados e outros dispêndios decorrentes, que influenciarão o nível de atividades existentes.

O impacto indireto é a segunda onda advinda dos efeitos diretos da atividade implantada. A partir da demanda dos fornecedores da empresa ou grupo de empresas envolvidas diretamente, ocorrerá uma série de contratações de gastos de fornecedores, com o aumento do consumo de insumos de produção local ou regional, incrementando a atividade econômica e assim o emprego no nível regional, gerando o crescimento econômico regional.

Os impactos induzidos correspondem à terceira onda de impacto econômico. É formado pelos gastos locais das famílias dos empregados com seus rendimentos. São gastos não relacionados diretamente com a atividade portuária e, sim, se referenciando, por exemplo, a despesas com aluguel, alimentação, lazer, educação e etc.

Este estudo ao focalizar os impactos provocados pela implantação do empreendimento portuário do TPA se baseou na metodologia de avaliação econômica desenvolvida pelo Bureau of Transport Economics da Austrália, assim como, se referenciou a outras originadas nas bibliografias consultadas como resumido na Tabela 1.

Tabela 1 - Resumo das metodologias e impactos na bibliografia analisada

\begin{tabular}{|l|l|l|l|l|l|l|}
\hline REFERÊNCIA & EMPREGOS & $\begin{array}{l}\text { RENDIMEN } \\
\text { TOSI } \\
\text { SALÁRIOS } \\
\text { milhões } \mathbf{( \$ )}\end{array}$ & $\begin{array}{l}\text { OUTPUT } \\
\text { milhões } \\
\mathbf{( \$ )}\end{array}$ & $\begin{array}{l}\text { IMPAC } \\
\text { TO FIS } \\
\text { CAL } \\
\text { milhões } \\
\mathbf{( \$ )}\end{array}$ & $\begin{array}{l}\text { VAB } \\
\text { milhões } \\
\mathbf{( \$ )}\end{array}$ & $\begin{array}{l}\text { MULTIPLICA } \\
\text { DORES }\end{array}$ \\
\hline $\begin{array}{l}\text { BTE (2001) } \\
\text { Port of } \\
\text { Gladstone }\end{array}$ & $\begin{array}{l}\text { Direto: } 738 \\
\text { Indireto: } 1020 \\
\text { Total: } 1758\end{array}$ & $\begin{array}{l}\text { Direto: \$44 } \\
\text { Indireto: \$24 } \\
\text { Total: \$68 }\end{array}$ & \$224 & - & \$139 & $\begin{array}{l}\text { Output: } 1,66 \\
\text { Remun.: } 0,030 \\
\text { Emprego: } 1,49\end{array}$ \\
\hline
\end{tabular}




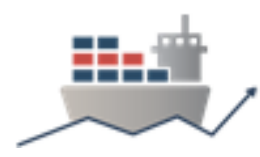

\begin{tabular}{|c|c|c|c|c|c|c|}
\hline $\begin{array}{l}\text { ERA (2007) } \\
\text { Port of San } \\
\text { Diego }\end{array}$ & $\begin{array}{l}\text { Direto: } \\
\text { 30.468. } \\
\text { Total: } 66.995\end{array}$ & $\begin{array}{l}\text { Sal. Total - } \\
\$ 4.500\end{array}$ & $\$ 9.600$ & $\$ 34.500$ & $\$ 5.040$ & \\
\hline $\begin{array}{l}\text { Merk; Hesse } \\
\text { (2012) } \\
\text { Port of } \\
\text { Hamburg }\end{array}$ & $\begin{array}{l}\text { Direto: } 78.902 \\
\text { Indireto: } \\
76.842 \\
\text { Total: } 155.744\end{array}$ & - & $\$ 8.300$ & - & - & 1,71 \\
\hline $\begin{array}{l}\text { Merk; } \\
\text { Nottebom } \\
\text { (2013) } \\
\text { Ports of } \\
\text { Rotterdam } \\
\text { Amsterdam } \\
\end{array}$ & $\begin{array}{l}\text { Roterdã } \\
\text { Direto: } 73.529 \\
\text { Amsterdã } \\
\text { Direto: } 4.930\end{array}$ & $\begin{array}{l}\text { Por } \\
\text { trabalhador } \\
\text { Roterdã } \\
\$ 0,16 \\
\text { Amsterdã } \\
\$ 0,12\end{array}$ & - & - & $\begin{array}{l}\text { Roterdã } \\
\$ 10.300 \\
\text { Amsterd } \\
\tilde{a} \\
\$ 1.600\end{array}$ & $\begin{array}{l}\text { Roterdã: } 1.13 \\
\text { Amsterdã: - }\end{array}$ \\
\hline $\begin{array}{l}\text { Merk; Li } \\
\text { (2013) } \\
\text { Hong Kong }\end{array}$ & $\begin{array}{l}\text { Direto: } 83.700 \\
\text { Indireto: } \\
29.300 \\
\text { Total: } 113.000\end{array}$ & per & - & - & $\$ 4.000$ & $\begin{array}{l}\text { VAB: } 1,6 \\
\text { Emprego: } 1,3\end{array}$ \\
\hline $\begin{array}{l}\text { BTE (2001) } \\
\text { Port of Mackay }\end{array}$ & $\begin{array}{l}\text { Direto: } 212 \\
\text { Indireto: } 289 \\
\text { Total - } 501\end{array}$ & $\begin{array}{l}\text { Direto: } \$ 10 \\
\text { Indireto: } \$ 7 \\
\text { Total: } \$ 17\end{array}$ & $\$ 56$ & - & $\$ 32$ & $\begin{array}{l}\text { Output: } 1,31 \\
\text { VAB: } 0,79 \\
\text { Remun: } 0,42 \\
\text { Emprego: } 1,43\end{array}$ \\
\hline
\end{tabular}

Fonte: Os autores.

A metodologia estabelecida pelo BTE da Austrália analisou o impacto tendo em vista as seguintes variáveis: Valor dos bens produzidos; Valor adicionado bruto - VAB; Rendimento das famílias e Número de empregos gerados no ano, como segue.

I - Valor dos bens produzidos: Considerou o volume de negócios produzido em cada atividade e aplicado à atividade de uma empresa, a uma instituição pública, a um programa social, a um cluster, local em que se concentram estabelecimentos ou prestadores de serviços relacionados a uma atividade econômica. (ZACCARELLI et al., 2008). Este indicador é divulgado pelas empresas em seus balanços.

II - Valor adicionado bruto - VAB: Na economia, denomina-se "valor adicionado em determinada etapa da produção, a diferença entre o valor bruto produzido nessa etapa (igual a vendas mais acréscimos de estoques) e os consumos intermediários (valores das matérias-primas ou insumos utilizados)" (SIMONSEN; CISNE, 1995, p. 130 apud Rodrigues, Melo, Lustosa, 2007). Do ponto de vista macroeconômico, a riqueza criada, ou valor adicionado, é o Produto Interno Bruto (PIB). Por analogia, o valor adicionado bruto pode ser considerado o PIB da empresa (KROETZ, 2000). De acordo com o IPEA, o Valor Adicionado Bruto é o valor que a atividade agrega aos bens e serviços consumidos no seu processo produtivo. É a contribuição ao Produto Interno Bruto pelas diversas atividades econômicas e obtida pela diferença entre 0 valor de produção e o consumo intermediário absorvido por essas atividades (IPEA, 2019).

III - Rendimento das Famílias: Rendimento dos empregados e colaboradores que atuam no setor analisado. Rendimento disponível para consumo.

IV - Número de empregos gerados no ano: Número de empregados como indicador de cálculo do efeito direto e indireto no mercado de trabalho analisado.

O modelo multisetorial de mensuração da participação relativa de cada setor econômico em um sistema produtivo é a principal ferramenta utilizada para o cálculo do impacto econômico de empreendimentos. O instrumental metodológico adota a 
técnica proposta pelo economista russo, naturalizado norte-americano, Wassily W. Leontief, que permite a identificação da interdependência das atividades produtivas com os insumos e produtos utilizados e decorrentes do processo de produção. Desta forma, em uma determinada atividade produtiva permite que se analise e mensure o seu impacto em um sistema econômico nacional ou regional. (IPEA, 2019).

A origem desse modelo está em um trabalho de 1785 de François Quesnay na obra Tableau Economique, conforme apontou Camilo (2007):

A relação de interdependência entre os setores foi apresentada primeiramente, em 1758, por François Quesnay na obra "Tableau Economique', considerada pioneira para descrever os fluxos da economia francesa. Pouco mais de um século depois, outro francês Leon Walras dava um novo passo ao publicar 'Elements d'Économie Politique Pure' em 1874, que por meio de um sistema de equações buscava determinar de forma simultânea todos os preços em uma economia, além do que, considerava os custos da produção em cada setor. (CAMILO, 2007).

Leontieff (1987), citado por Guilhoto (2004), observou:

A análise de Insumo-Produto é uma extensão prática da teoria clássica de interdependência geral que vê a economia total de uma região, país, ou mesmo do mundo todo, como um sistema simples, e parte para descrever e para interpretar a sua operação em termos de relações estruturais básicas observáveis (LEONTIEF, 1987, p. 86, apud Guilhoto, 2004).

Desse modo, como se mostrou, a técnica de Matriz Insumo-Produto de Leontief tem origem no Século XVII, tendo incorporado ao longo do tempo diversas contribuições de economistas, conforme mostra a Figura 4 proposta em Guilhoto (2004, pg. 3).

Figura 4 - Esquema das origens da teoria de Leontief

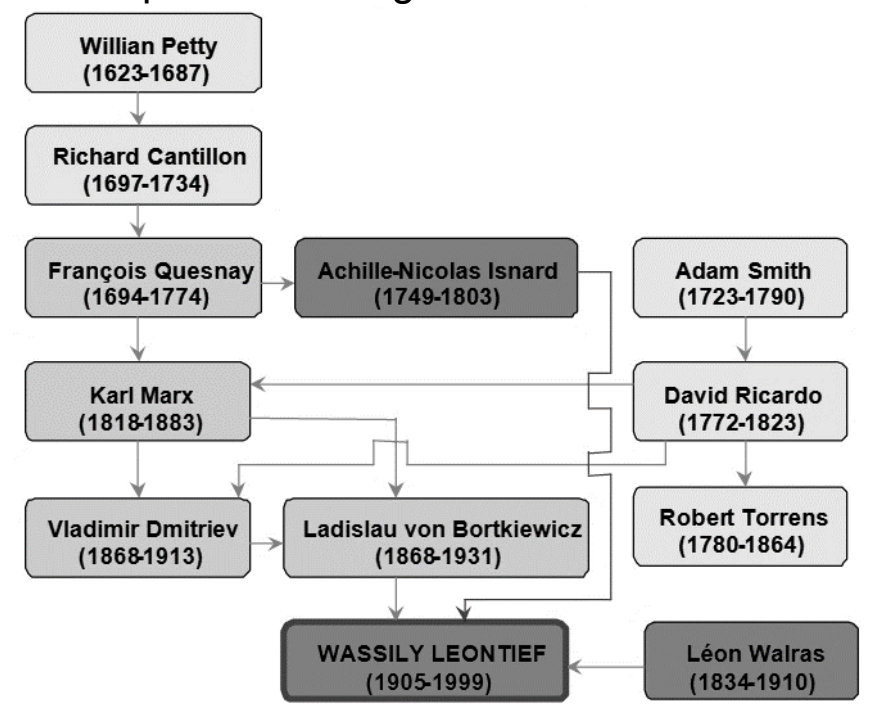

Fonte: Guilhoto, 2004, p. 3.

O modelo da matriz de insumo-produto proposto por Leontief pode ainda ser utilizado para análise do impacto econômico de empreendimentos por considerar como os sistemas econômicos funcionam para equacionar a demanda e a oferta de bens e serviços em uma vasta rede de atividades e um de seus objetivos é desenvolver uma radiografia de como os setores se inter-relacionam. O resultado é 
uma visão de como as economias funcionam e a dimensão dos impactos entre setores interdependentes. É formalmente demonstrado em uma tabela conhecida como uma matriz de insumo-produto.

Para a construção de uma matriz insumo-produto referenciada a uma região é necessário levantamento de informações sobre cada empresa e organização existente, englobando seus fluxos de vendas, de compras, de suprimentos, transportes, tributos e o rendimento dos trabalhadores.

No Brasil, o responsável oficial pela produção desse tipo de estatística, a Matriz Insumo-Produto do país e dos estados é o Instituto Brasileiro de Geografia e Estatística - IBGE, instituição vinculada ao Ministério da Economia que atua em parceria com institutos de estudos socioeconômicos estaduais. O Sistema de Contas Nacionais, gerenciado pelo IBGE, segue as recomendações de um manual internacional, o System of National Accounts 2008, SNA 2008 (IBGE, 2015).

A publicação da matriz insumo-produto nacional é feita desde 1970, a cada cinco anos. Embora essa matriz seja calculada para alguns estados da Federação, ainda não se conta com uma matriz insumo-produto do estado do Maranhão, conforme afirmou o Presidente do IMESC - Instituto de Estudos Socioeconômicos do Estado do Maranhão:

\begin{abstract}
Colocamos como demandas para o IBGE, o apoio para a construção de uma Pesquisa Industrial Mensal - Produção Física (PIM-PF) para o Estado do Maranhão (os Estados da Bahia, Pernambuco e Ceará já a dispõem). Solicitamos também apoio para construir uma Matriz-Insumo Produto específica para o Estado do Maranhão (tem para o Nordeste e para vários estados nordestinos, mas não há para o Maranhão), assim como o PIB Trimestral. Os três são instrumentos interligados e fundamentais para avançarmos no diagnóstico, monitoramento e avaliação de políticas de adensamento de cadeias produtivas e de inclusão sócio produtiva. (IMESC, 2019).
\end{abstract}

Com a ausência de uma matriz insumo-produto é necessário realizar uma adaptação na metodologia de impacto econômico com a utilização de multiplicadores disponíveis em pesquisas semelhantes.

\title{
3 PROCEDIMENTOS METODOLÓGICOS
}

A presente pesquisa foi desenvolvida com a utilização de quatro metodologias: pesquisa bibliográfica; pesquisa documental; entrevista e metodologia de análise de impacto econômico proposta pelo Bureau of Transport Economics da Austrália.

A pesquisa bibliográfica teve como objetivo apresentar os conceitos fundamentais, estabelecendo uma estrutura teórica e um quadro conceitual dos seus aspectos mais relevantes.

A pesquisa documental, como método, ainda está em fase de discussão, elaboração e refinamento no campo científico, principalmente quando utilizada em outras áreas de pesquisa fora do campo da história. É classificada como técnica de coleta de dados, ou procedimento metodológico, ou delineamento de pesquisa. Porém, é claro seu reconhecimento pelo seu potencial de utilização em diversas áreas e pelo aprendizado gerado pela sua aplicação (BELTRÃO; NOGUEIRA, 2011).

Os documentos utilizados para a pesquisa documental foram $\bigcirc$ Balanço Patrimonial da Empresa Maranhense de Administração Portuária - EMAP e documentos fornecidos pela empresa Grão Pará Multimodal os documentos: Estudo 
de Viabilidade Técnica e Econômica; Memorial Descritivo e Planilha Orçamentária com o CAPEX - Capital Expenditure (Despesas de Capital).

As entrevistas foram semiestruturadas foram com dirigentes da Grão Pará Multimodal e também com gestores de terminais privados e de portos públicos. Com a Grão Pará Multimodal o objetivo da entrevista foi entender questões específicas do projeto do TPA e com os outros entrevistados foi compreender as algumas práticas de despesas, receitas e investimentos.

A metodologia de análise de impacto econômico proposta pelo Bureau of Transport Economics se baseia no cálculo do impacto direto, indireto e induzido. Essa metodologia foi escolhida devido pesquisa realizada e demonstrada na Tabela 1. Ela foi adaptada para a realidade do TPA, ou seja, um porto novo a ser implantado em área privada e disponível (greenfield).

O impacto direto foi calculado com o Valor dos Serviços Prestados que foi informado no CAPEX. O Valor Adicionado Bruto foi calculado considerando o Valor dos Serviços Prestados e dele subtraindo o Consumo Intermediário. No Consumo Intermediário foi considerado a taxa de 0,2428 que foi escolhida pois é a mesma taxa utilizada no Balanço Patrimonial da EMAP - Empresa Maranhense de Administração Portuária, um porto que movimenta o mesmo tipo de mercadorias, granéis sólidos e líquidos, portanto apresenta uma estrutura de custos e despesas semelhantes. $O$ Valor dos Serviços Prestados. Consumo Intermediário e o Valor Adicionado Bruto estão demonstrados na Tabela 3. O rendimento das famílias e o número de empregos gerados (demonstrados na Tabela 4). Estes valores foram obtidos com a análise documental e entrevista com os gestores da Grão Pará Multimodal e com gestores de Terminais e Portos Semelhantes como o Porto do Itaqui, Terminal Marítimo de Ponta da Madeira (VALE) e TEGRAM - Terminal de Grãos do Maranhão.

$O$ impacto indireto e induzido dessas quatro variáveis foi calculado com a utilização de multiplicadores pesquisados na literatura internacional aplicados em portos semelhantes (demonstrados na Tabela 5). Estes multiplicadores aplicados nos impactos diretos geraram o impacto indireto e induzido (demonstrados nas Tabelas 6, 7, 8 e 9).

Todas as projeções do impacto econômico foram elaboradas considerando um horizonte de 24 anos, sendo o primeiro ano 2024, início da movimentação portuária e o último ano 2048, último ano de movimentação de acordo com o contrato assinado com a ANTAQ.

\section{TERMINAL PORTUÁRIO DE ALCÂNTARA - TPA}

O Terminal Portuário de Alcântara - TPA, que já conta com a autorização da Agência Nacional de Transportes Aquaviários - ANTAQ para sua implantação, será construído na Ilha do Cajual situada na Baía de São Marcos, conforme mostra a Figura 5. 
Figura 5 - Localização do TPA

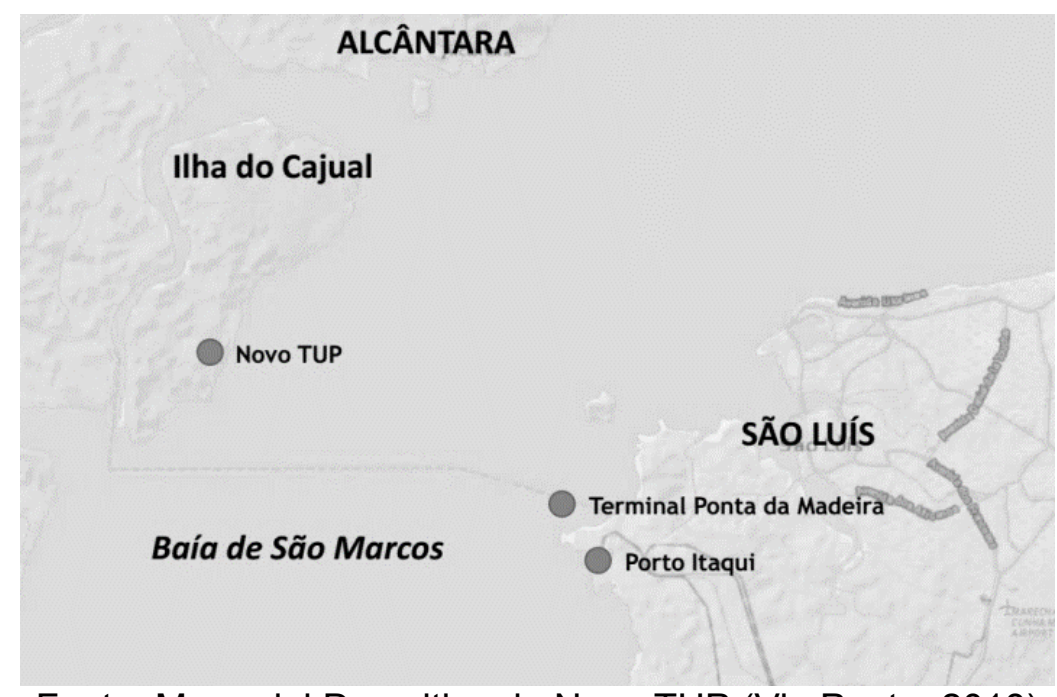

Fonte: Memorial Descritivo do Novo TUP (Via Ponte, 2018)

O acesso rodoviário se dará por ligação à rodovia atual, a BR-308 junto a Cujupe. A acessibilidade será garantida da seguinte forma:

- BR-308 (que serve o terminal de Ferry-Boat - São Luís - Cujupe), com ligação futura ao TUP;

- BR-316 no sentido norte/noroeste em direção a Belém (PA);

- BR-316 no sentido sudeste em direção a Teresina (PI), e daí a Fortaleza (CE);

- BR-222 (via BR-316) no sentido nordeste, em direção a São Luís (MA);

- BR-222 (via BR-316) no sentido sudoeste em direção a Açailândia (MA), e daí aos Estados do interior (Tocantins (TO), Brasília (DF), Mato Grosso (MT), entre outros).

O acesso ferroviário será feito a partir de ramal a ser implantado, ligando a Estrada de Ferro de Carajás (EFC) ao novo TPA e possíveis futuras ligações com a Ferrovia Norte Sul (FNS) e com Ferrovia Transnordestina.

Em sua Fase 1, o TPA prevê operar até 2024 com dois berços para movimentação de minério e granéis agrícolas, principalmente soja em grão. Na Fase 2 prevista para 2030, haverá aumento da capacidade para o escoamento de minérios e grãos e na Fase 3, a construção de mais dois berços para atendimento de outras demandas de movimentação, tais como, minério de ferro; outros produtos do agronegócio; cobre; contêineres; carvão e carga geral.

O complexo portuário ocupará uma área de 882 ha, operando, principalmente três tipos de cargas: (i) minério de ferro e ferro gusa; (ii) grãos alimentares; e (iii) e carga geral, a serem localizadas em zonas distintas do retroporto e denominadas: (i) Terminal de Minério; (ii) Terminal Agro e (iii) Terminal de Carga Geral. A área pretendida em terra será $11.795 .758 \mathrm{~m}^{2}$ e sobre água é de $66.097 \mathrm{~m}^{2}$ (Via Ponte, 2018).

Sobre a projeção de movimentação das duas principais cargas, minério e graneis alimentares, segue uma projeção da movimentação portuária (Tabela 2). 
Tabela 2 - Projeção da movimentação portuária (Milhares de ton)

\begin{tabular}{|c|r|r|r|}
\hline Ano & Minério de Ferro & Granéis & Total \\
\hline 2024 & 50.000 & 20.000 & 70.000 \\
\hline 2025 & 100.000 & 20.000 & 120.000 \\
\hline 2026 & 100.000 & 20.000 & 120.000 \\
\hline 2027 & 125.000 & 20.000 & 145.000 \\
\hline 2028 & 125.000 & 20.000 & 145.000 \\
\hline 2029 & 125.000 & 20.000 & 145.000 \\
\hline 2030 & 125.000 & 20.000 & 145.000 \\
\hline 2031 & 140.000 & 20.000 & 160.000 \\
\hline 2032 & 140.000 & 20.000 & 160.000 \\
\hline 2033 & 140.000 & 20.000 & 160.000 \\
\hline 2034 & 140.000 & 30.000 & 170.000 \\
\hline 2035 & 140.000 & 30.000 & 170.000 \\
\hline 2036 & 140.000 & 30.000 & 170.000 \\
\hline 2037 & 140.000 & 30.000 & 170.000 \\
\hline 2038 & 140.000 & 30.000 & 170.000 \\
\hline 2039 & 140.000 & 40.000 & 180.000 \\
\hline 2040 & 140.000 & 40.000 & 180.000 \\
\hline 2041 & 140.000 & 40.000 & 180.000 \\
\hline 2042 & 140.000 & 40.000 & 180.000 \\
\hline 2043 & 140.000 & 40.000 & 180.000 \\
\hline 2044 & 140.000 & 40.000 & 180.000 \\
\hline 2045 & 140.000 & 40.000 & 180.000 \\
\hline 2046 & 140.000 & 40.000 & 180.000 \\
\hline 2047 & 140.000 & 40.000 & 180.000 \\
\hline 2048 & 140.000 & 40.000 & 180.000 \\
\hline Total & 3.270 .000 & 750.000 & 4.020 .000 \\
\hline \hline Fon & Grä & Para & \\
\hline
\end{tabular}

Fonte: Grão Pará Multimodal (2018)

Dessa forma, o TPA irá se juntar a outras instalações portuárias da Baía de São Marcos, como o Porto de Itaqui, administrado pela EMAP - Empresa Maranhense de Administração Portuária Portos, empresa pública ligada ao governo maranhense, o Terminal Marítimo de Ponta da Madeira da VALE e o Porto da Alumar que, atualmente, compõem o Complexo Portuário do Maranhão.

\section{RESULTADOS}

O impacto econômico do TPA, conforme mencionado, foi estimado em três dimensões: direto, indireto e induzido (Figura 1) e suas estimativas são apresentadas a seguir.

\subsection{Impacto direto}

O impacto direto do TPA, conforme metodologia aplicada, corresponde ao Valor dos Serviços Prestados, o Valor Adicionado Bruto, o rendimento das famílias e o número de empregos gerados. Todos estes valores e projeções foram coletados 


\section{CIDESPORT/2019}

Congresso Internacional

de Desempenho Portuário

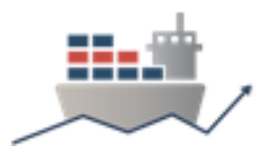

diretamente com os gestores do TPA, em entrevistas com profissionais de terminais semelhantes, pela análise de demonstrativos financeiros de portos semelhantes e documentos do projeto TPA (CAPEX, Memorial Descritivo, Estudo de Viabilidade Técnica e Econômica). Os dados foram estimados para o período de 2024 (início das operações do TPA) até 2048.

O Valor dos Serviços Prestados é resultante da multiplicação das taxas a serem cobradas pela movimentação dos produtos pelo volume previsto de transporte, resultando (Tabela 3) em uma evolução de $R \$ 3,8$ bilhões em 2024 para $R \$$ 40,6 bilhões em 2048, ou seja, crescendo mais de dez vezes no período, conforme as estimativas disponibilizadas pelo TPA.

A estimativa do Valor Adicionado Bruto (VAB) corresponde à subtração ao valor dos serviços prestados dos gastos com o consumo intermediário, isto é, o dispêndio com insumos e recursos necessários para a sua prestação. Para tanto, utilizou-se a relação média entre valor de serviços e insumos, conforme informações obtidas nos demonstrativos contábeis da EMAP dos anos de 2015 a 2017 (24,3\%). A Tabela 3 mostra as estimativas de VAB para o TPA com os valores evoluindo de R $\$ 2,9$ bilhões para $\mathrm{R} \$ 30,8$ bilhões, acompanhando o crescimento do valor dos serviços prestados. Todo o trabalho de cálculo do impacto econômico foi realizado para o período de 2024 a 2045. Porém, com o objetivo de simplificar a apresentação dos resultados e adequar ao formato do artigo científico os resultados serão apresentados a seguir com os dados de cinco anos: 2024; 2030; 2036; 2042 e 2048.

Tabela 3 - Estimativa dos valores dos serviços prestados em $\mathrm{R} \$$ milhões

\begin{tabular}{|c|r|r|r|}
\hline \multicolumn{1}{|c|}{ Ano } & $\begin{array}{c}\text { Valor dos Serviços } \\
\text { Prestados }\end{array}$ & $\begin{array}{c}\text { Consumo } \\
\text { Intermediário }\end{array}$ & $\begin{array}{c}\text { Valor Adicionado Bruto - } \\
\text { VAB }\end{array}$ \\
\hline $\mathbf{2 0 2 4}$ & $3.832,2$ & 930,5 & $2.901,7$ \\
\hline $\mathbf{2 0 3 0}$ & $11.311,4$ & $2.746,4$ & $8.565,0$ \\
\hline $\mathbf{2 0 3 6}$ & $18.897,3$ & $4.588,3$ & $14.309,0$ \\
\hline $\mathbf{2 0 4 2}$ & $28.511,8$ & $6.922,7$ & $21.589,1$ \\
\hline $\mathbf{2 0 4 8}$ & $40.628,0$ & $9.864,5$ & $30.763,5$ \\
\hline
\end{tabular}

Fonte: Dados da pesquisa.

O rendimento das famílias disponível para consumo para o TPA foi calculado com base nas estimativas de empregados disponibilizadas pela empresa (Tabela 4) às quais se aplicou a remuneração média líquida dos colaboradores diretos do TEGRAM, terminal de granéis sólidos do Porto de Itaqui, permitindo-se chegar ao rendimento direto disponibilizado para consumo na Tabela 4. Ou seja, o rendimento líquido disponibilizado para consumo se inicia em 2024 com $R \$ 173$, 3 milhões e vai aumentando progressivamente para alcançar em $2048 \mathrm{R} \$ 459,5$ milhões, um aumento de $165,1 \%$.

Tabela 4 - Estimativa dos empregos diretos e do rendimento das famílias em $\mathrm{R} \$$ milhões

\begin{tabular}{|r|l|r|}
\hline Ano & $\begin{array}{l}\text { Número de } \\
\text { empregos } \\
\text { diretos }\end{array}$ & $\begin{array}{l}\text { Rendimento } \\
\text { disponibilizado } \\
\text { para consumo }\end{array}$ \\
\hline $\mathbf{2 0 2 4}$ & 3.000 & 172,3 \\
\hline $\mathbf{2 0 3 0}$ & 3.000 & 172,3 \\
\hline
\end{tabular}




\begin{tabular}{|l|r|r|}
$\mathbf{2 0 3 6}$ & 6.000 & 344,6 \\
\hline $\mathbf{2 0 4 2}$ & 8.000 & 459,5 \\
\hline $\mathbf{2 0 4 8}$ & 8.000 & 459,5 \\
\hline
\end{tabular}

Fonte: Dados da pesquisa

\subsection{Impacto indireto e induzido}

A quantificação do impacto econômico indireto e induzido é complexa e verificou-se que na literatura especializada é aplicada a técnica de Matriz InsumoProduto de Leontief (BTE, 2001; ERA, 2007; Merk e Hesse, 2012; M. Merk e Nottebom, 2013; Merk e Li, 2013; Furtado, 2015; CEGE, 2011).

Para a aplicação direta da Matriz Insumo-Produto de Leontief é necessária a existência da matriz insumo-produto do estado onde se localiza o empreendimento com dados históricos dos valores dos serviços prestados ou bens produzidos, do rendimento das famílias, do número de empregos e dos valores de VAB.

No entanto, conforme já mencionado, não existem para o estado do Maranhão estimativas produzidas da sua matriz insumo-produto e, assim, nossa análise se baseou na projeção do TPA para o período de 2024 a 2048, ou seja, a partir da previsão da entrada em operação do TPA, não se tratando de sua análise histórica.

Neste sentido, utilizamos as estimativas de multiplicadores de efeito indireto e induzido de pesquisa semelhante de análise de impacto econômico de empreendimentos portuários realizada por Furtado (2015), apresentadas na Tabela 5.

Tabela 5 - Multiplicadores para análise indireta e induzida

\begin{tabular}{|l|c|c|c|c|}
\hline \multicolumn{5}{|c|}{ MULTIPLICADORES } \\
\hline Efeito & $\begin{array}{c}\text { Valor dos } \\
\text { Serviços } \\
\text { Produzidos }\end{array}$ & Rendimentos & VAB & Emprego \\
\hline Indireto & 0,61 & 1,21 & 0,90 & 1,19 \\
\hline Induzido & 0,17 & 0,53 & 0,39 & 1,05 \\
\hline
\end{tabular}

Fonte: Furtado 2015.

As Tabelas 6, 7, 8 e 9 apresentam os resultados anuais obtidos para o Valor dos Serviços Prestados, Valor Adicionado Bruto, Rendimentos das Famílias e Número de Empregados com a utilização dos multiplicadores, chegando-se ao resultado dos efeitos indiretos e induzidos.

Tabela 6 - Valor dos Serviços Prestados em R \$ milhões

\begin{tabular}{|r|c|c|c|c|}
\hline Ano & $\begin{array}{c}\text { Valor dos Serviços } \\
\text { Prestados }\end{array}$ & Efeito Indireto & Efeito Induzido & Impacto total \\
\hline $\mathbf{2 0 2 4}$ & $3.832,2$ & $2.331,5$ & 643,4 & $6.807,1$ \\
\hline $\mathbf{2 0 3 0}$ & $11.311,4$ & $6.881,9$ & $1.899,2$ & $20.092,5$ \\
\hline $\mathbf{2 0 3 6}$ & $18.897,3$ & $11.497,1$ & $3.172,9$ & $33.567,3$ \\
\hline $\mathbf{2 0 4 2}$ & $28.511,8$ & $17.346,6$ & $4.787,1$ & $50.645,5$ \\
\hline $\mathbf{2 0 4 8}$ & $40.628,0$ & $24.718,1$ & $6.821,4$ & $72.167,5$ \\
\hline
\end{tabular}

Fonte: Dados da pesquisa. 


\section{CIDESPORT/2019}

Congresso Internacional

de Desempenho Portuário

Tabela 7 - Valor Adicionado Bruto em R\$ milhões

\begin{tabular}{|c|c|c|c|c|}
\hline Ano & $\begin{array}{l}\text { Valor Adicionado } \\
\text { Bruto }\end{array}$ & Efeito Indireto & Efeito Induzido & Impacto total \\
\hline 2024 & $2.901,7$ & $2.615,4$ & $1.137,7$ & $6.654,8$ \\
\hline 2030 & $8.565,0$ & $7.719,7$ & $3.358,1$ & $19.642,9$ \\
\hline 2036 & $14.309,0$ & $12.896,9$ & $5.610,2$ & $32.816,1$ \\
\hline 2042 & $21.589,1$ & $19.458,5$ & $8.464,6$ & $49.512,2$ \\
\hline 2048 & $30.763,5$ & $27.727,5$ & $12.061,7$ & $70.552,6$ \\
\hline
\end{tabular}

Fonte: Dados da pesquisa.

Tabela 8 - Rendimento das famílias em R $\$$ milhões

\begin{tabular}{|c|c|c|c|c|}
\hline Ano & $\begin{array}{l}\text { Rendimento } \\
\text { disponibilizado para } \\
\text { consumo }\end{array}$ & Efeito Indireto & Efeito Induzido & Impacto total \\
\hline 2024 & 172,3 & 208,9 & 90,9 & 472,1 \\
\hline 2030 & 172,3 & 208,9 & 90,9 & 472,1 \\
\hline 2036 & 344,6 & 417,8 & 181,8 & 944,2 \\
\hline 2042 & 459,5 & 557,1 & 242,3 & $1.258,9$ \\
\hline 2048 & 459,5 & 557,1 & 242,3 & $1.258,9$ \\
\hline
\end{tabular}

Fonte: Dados da pesquisa.

Tabela 9 - Número de empregados

\begin{tabular}{|r|r|r|r|r|}
\hline Ano & $\begin{array}{l}\text { Número de } \\
\text { empregos diretos }\end{array}$ & Efeito Indireto* & Efeito Induzido** & $\begin{array}{l}\text { Empregados } \\
\text { totais }\end{array}$ \\
\hline $\mathbf{2 0 2 4}$ & 3.000 & 9.000 & 3.159 & 15.159 \\
\hline $\mathbf{2 0 3 0}$ & 3.000 & 9.000 & 3.159 & 15.159 \\
\hline $\mathbf{2 0 3 6}$ & 6.000 & 18.000 & 6.318 & 30.318 \\
\hline $\mathbf{2 0 4 2}$ & 8.000 & 24.000 & 8.424 & 40.424 \\
\hline $\mathbf{2 0 4 8}$ & 8.000 & 24.000 & 8.424 & 40.424 \\
\hline
\end{tabular}

*relação de empregos diretos e indiretos obtidos de informações dos gestores do TPA.

**multiplicadores de efeito induzido, indicadores de Furtado (2015).

Os resultados obtidos demonstram um impacto econômico significativo e importante para a área de influência mediata do TPA, indicando que além da viabilidade econômica privada do empreendimento, ele se mostra bastante positivo para sua área de influência e abrangência.

\section{CONCLUSÕES}

O estudo se concentrou na problemática da quantificação do impacto econômico da atividade portuária, em suas dimensões direta, indireta e induzida, na 


\section{CIDESPORT/2019}

Congresso Internacional

de Desempenho Portuário

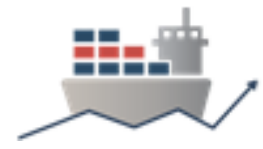

sua área de influência imediata, especificamente do Terminal Portuário de Alcântara, empreendimento greenfield localizado na Baia de São Marcos no estado do Maranhão, pertencente a empresa Grão Pará Multimodal.

O porto, inicialmente, será dedicado à movimentação de granéis sólidos (minerais e grãos agrícolas), prevendo a operação de carga seca conteinerizada em sua Fase 3.

Este estudo objetivou contribuir para o entendimento da importância de um empreendimento portuário como o TPA no nível local, regional e nacional. Seu impacto econômico total e por consequência na relação porto-cidade. Utilizamos a metodologia proposta pelo Bureau of Transport Economic da Austrália (2001) e mais especificamente os multiplicadores para análise de impacto indireto e induzido propostos por Furtado (2015).

Os resultados obtidos mostraram um valor e evolução significativos, sendo que o impacto total do Valor Adicionado Bruto se inicia com R\$ 6,7 bilhões em 2024, prevendo-se atingir R\$70,5 bilhões em 2048. Note-se que o VAB expressa a contribuição de uma atividade econômica para o PIB de sua região. Em relação aos empregos, o impacto total em 2024 foi estimado em 15.159, atingindo 40.424 em 2048, correspondendo ao impacto total de rendimentos das famílias de $R \$ 472,1$ milhões em 2024, alcançando R \$ 1,2 bilhões em 2048.

Em termos percentuais, esses impactos em 2024 irão representar um acréscimo no PIB dos 3 municípios de $2.700 \%$ e de $8 \%$ para o Estado do Maranhão. Com uma taxa de inflação de 4,3\% a. a., os R $\$ 70,5$ bilhões de Valor Adicionado Bruto em 2048 indicam um valor atual de $\mathrm{R} \$ 25,6$ bilhões, ou seja, representando acréscimo de $30 \%$ ao PIB atual do Maranhão. Em termos médios, o impacto do TPA no PIB atual do Maranhão representará um acréscimo de $20 \%$ no período 2024-2048.

Esses números indicam a oportunidade e significação deste empreendimento para sua área de influência e, comprovando o papel dos portos para contribuir para a melhoria das condições de movimentação de produtos (riquezas) e beneficiando pessoas (geração de renda).

\section{REFERÊNCIAS}

BELTRÃO, R. E. V.; NOGUEIRA, F. A. A Pesquisa Documental nos Estudos Recentes em Administração Pública e Gestão Social no Brasil. In XXXV Encontro da Anpad. Rio de Janeiro, RJ, 4-7 de setembro de 2011. Disponível em: http://www.anpad.org.br/admin/pdf/EPQ2700.pdf. Acesso em 21 de março de 2018.

BOOZ \& Co. Análise e Avaliação da Organização Institucional e da Eficiência de Gestão do Setor Portuário Brasileiro. 2012. Disponível em https://web.bndes.gov.br/bib/jspui/handle/1408/7668 . Acesso em 14 de março de 2019.

BTE - Bureau of Transport Economics. Regional Impact of the Gladstone. (2001). Regional Impact of the Port of Mackay, (2001). Regional Impact of ports, Report $n^{\circ} 101$, BTE, Canberra, (2000).

CEGE - Centro de Estudos de Economia e Gestão do Instituto Superior de Economia e Gestão - ISEG. Estudo sobre o impacto econômico dos portos de Setúbal e Sesimbra, 2011. 


\section{CIDESPORT/2019}

Congresso Internacional

de Desempenho Portuário

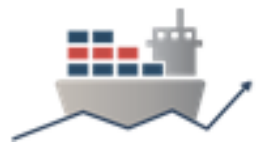

CAMILO, N. Teoria e Prática na Utilização da Matriz Insumo-Produto como

Ferramenta de Pesquisa. RNTI. Revista Negócios e Tecnologia da Informação. v. 2, p. 34-50, 2007. Disponível em:

<http://publica.fesppr.br/index.php/rnti/issue/viewFile/5/39>. Acesso em 10 de março de 2019.

CUTRIM, S. S.; BOTTER, R. C.; ROBLES, L. T. Proposta de um novo modelo de governança portuária para o Brasil. Revista Eletrônica de Estratégia \& Gestão. Florianópolis, v.11, Ed. Especial 2, 2018.

ERA - Economics Research Associates. Economic and Fiscal Impacts of the Port of San Diego, 2007.

FURTADO, N. M. F. S. O Impacto Económico do Porto de Ponta Delgada. Dissertação de Mestrado em Economia. Departamento de Economia e Gestão. Universidade dos Açores. Outubro, 2015.

GRÃO PARÁ MULTIMODAL. CAPEX - Capital Expenditure, 2018.

GIL, A. Métodos e técnicas de pesquisa social. $6^{a}$. ed. São Paulo: Atlas, 2008.

GUILHOTO, J. J. M. Análise de Insumo-Produto: Teoria e Fundamentos. Março, 2004. Disponível em:

<http://www.erudito.fea.usp.br/PortalFEA/Repositorio/835/Documentos/Guilhoto\%20I nsumo\%20Produto.pdf>. Acesso em 18 de março de 2019.

IBGE. Matriz de Insumo-Produto Brasil. 2015. Disponível em:

IBGE. Cidades. O Brasil em síntese. Disponível em: https://cidades.ibge.gov.br/ Consultado em 10/05/2019.?

https://www.ibge.gov.br/estatisticas-novoportal/economicas/contas-nacionais/9085matriz-de-insumo-produto.html?=\&t=o-que-e. Acesso em 10 de março de 2019.

IMESC. A visita do Presidente do IBGE ao Maranhão e os avanços do Sistema de Planejamento do Estado. Disponível em

http://imesc.ma.gov.br/portal//mprensa/artigos/7 . Consultado em 14/02/2019. 2019.

IPEA. Contas Nacionais. Disponível em:

www.ipeadata.gov.br/doc/contas\%20nacionais-conceitos.doc. Acesso em 10 de março de 2019.

Matriz Insumo Produto. Disponível em:

http://www.ipea.gov.br/redeipea/index.php?option=com_content\&view=article\&id=98: matriz-insumo-produto-regional\&catid=89:projetos-de-pesquisa\&ltemid=206. Acesso em 20 de março de 2019.

JOUILI, T. A.; ALLOUCHE, M. A. Impacts of Seaport Investment on the Economic Growth. PROMET - Traffic \&Transportation, Vol. 28, N. 4, p. 365-370, 2016.

KROETZ, C. E. S. Balanço Social: teoria e prática. São Paulo: Atlas, 2000.

LEONTIEF, W. (1987). "Input-Output Analysis". em Eatwell, J., M. Milgate, e P. Newman (eds.). The New Palgrave. A Dictionary of Economics, vol. 2., pp.860-64 apud Guilhoto, J. J. M. Análise de insumo-produto: teoria e fundamentos.

Universidade de São Paulo. Disponível em 


\section{CIDESPORT/2019}

Congresso Internacional

de Desempenho Portuário

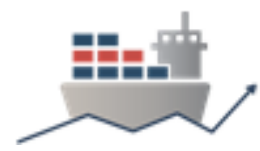

http://www.erudito.fea.usp.br/PortalFEA/Repositorio/835/Documentos/Guilhoto\%20In sumo\%20Produto.pdf. Acesso em 04 de março de 2019.

LEVINSON, M. The Box - How the Shipping Container Made the World Smaller and the World Economy Bigger. USA: Princeton University Press. 2006.

MEERSMAN, H.; VAN DE VOORDE, E.; VANELSLANDER, H. Port pricing. Considerations on economic principles and marginal costs. European Journal of Transport and Infrastructure Research 3, 371-386, 2003.

VIA PONTE, Memorial Descritivo do Novo TUP. Capítulo V da documentação de habilitação, 2018.

MERK, O., HESSE, M. The Competitiveness of Global Port-Cities: The Case of Hamburg - Germany, (2012).

MERK, O., NOTTEBOM T. The Competitiveness of Global Port-Cities: The Case of Rotterdam/Amsterdam - the Netherlands, (2013).

MERK, O., LI, J. The Competitiveness of Global Port-Cities: The case of Hong Kong - China, (2013).

MUSSO, E.; FERRARI, C.; BENACCHIO, M. Port investment: Profitability, economic impact and financing. In Port Economics. Research in Transportation Economics, Volume 16, p. 171-218. U. K.: Elsevier Ltd., 2006.

MONIÉ, F.; VIDAL, S. M. S. C.; Cidades, portos e cidades portuárias na era da integração produtiva. RAP, Rio de Janeiro. N 40. Nov./Dez. 2006.

NOTTEBOOM, T. E.; RODRIGUE, J. Port regionalization : towards a new phase in port development. Maritime Policy \& Management, n. March 2012, p. 37-41, 2005.

ROBLES, L. T. Organização e Estrutura Portuárias. Rio de Janeiro: SESES, 2016.

RODRIGUE, J. P.; SCHULMAN, J. The Economic Impacts of Port Investment. In The Geography of Transport System. Rodrigue, J. P.; Comtois, C.; Slack B. $4^{\text {th }}$ Ed. 2017. Disponível em https://transportgepgraphy.org/?page_id=9435. Acesso em 19 de abril de 2019.

SIMONSEN, M. H.; CYSNE, R. P. Macroeconomia. 2 ed. São Paulo: Atlas, 1995 apud RODRIGUES, F. F; MELLO, M. C. B.; LUSTOSA, P. R. B. Valor Adicionado Bruto ou Valor Adicionado Líquido: o Tratamento da Depreciação na Demonstração do Valor Adicionado. XXXI EnANPAD - Encontro Nacional dos Programas de PósGraduação em Administração, 2007.

STRAUSS-WIEDER INCORPORATION. The Economic Impact of the New York-New Jersey port/Maritime Industry. EUA, (2011).

ZACCARELLI, S. B.; TELLES, R; SIQUEIRA, J. P. L.; BOAVENTURA, J. M. G.; 